\title{
The diagnosis of autism spectrum disorder in Nghe An province, Vietnam
}

\author{
S.C. Thuc ${ }^{1}$, K.A.T. Thi ${ }^{1}$, L.T. Ngoc ${ }^{2}$ and H.D. Vinh ${ }^{3 *}$ \\ ${ }^{1}$ Vinh Medical University and Vinh Medical University Hospital \\ ${ }^{2}$ Nghe An Pediatric Hospital \\ ${ }^{3}$ University of Medicine Pham Ngoc Thach \\ Corresponding author: H.D. Vinh \\ E-mail: hiepdv@pnt.edu.vn
}

Genet. Mol. Res. 20 (1): gmr18736

Received December 30, 2019

Accepted April 20, 2020

Final Revision January 25, 2021

Published March 29, 2021

DOI http://dx.doi.org/10.4238/gmr18736

\begin{abstract}
Autism spectrum disorders (ASD) are characterized by speech and social behavior problems. Worldwide prevalence of ASD was 1 in 59 children in 2014. According to research of 2019, the prevalence of ASD in Vietnam was significantly higher in urban $1.238 \%$ than in rural areas $0.580 \%$. In the absence of specific biological markers, diagnosis of ASD is made based on the behavioral and psychological characteristics of the patient. Four hundred preschool teachers from 187 schools were trained to identify signs of ASD. Among 441 children with autistic signs presented by preschool teachers, $(34.9 \%$ were treated. Medical management included typical antipsychotics, atypical antipsychotics, antidepressants, selective serotonin reuptake inhibitors, $\alpha 2$ adrenergicagonists, $\beta$-adrenergic antagonists, mood stabilizers, and anticonvulsants. As expected, the most common group of children who had ASD symptoms were children 18-24 months old (35.4\%). The incidence of ASD among boys and girls was 75.5 and $24.5 \%$, respectively. Children living in cities were most affected by ASD 41.5\%. Following treatment, severe ASD levels decreased from 89.5 to $45 \%$. The decrease in severe ASD demonstrates that diagnosis and therapy functions. In Nghe An, there has been no research on the epidemiology of ASD in children. Therefore, the detection and
\end{abstract}


organization of treatment and teaching of children are necessary in order to create conditions for children to develop a fuller personality, integrate into the community, and reduce the burden for themselves, their family, and society.

Key words: Autism spectrum disorder; Vietnam; Evidence-based medicine; Early diagnostic; Hobblers; Children

\section{INTRODUCTION}

Autism Spectrum Disorders (ASD) are defined as a group of disorders involving changes in social behavior and verbal communication. In most cases the conditions are apparent during the first five years of life (Yen, 2014; World Health Organization, 2019). Intellectual disability is observed in more than half of ASD cases (Baio et al., 2018).

\section{Prevalence of ASD}

The prevalence of ASD has increased from 1 in 150 children in 2000 to 1 in 59 children in 2014 (Hossain et al., 2017). Recent evidence suggests that there is an upward trend in ASD prevalence in South Asian countries (Baxter et al., 2015). The 2014 screening study by Yen et al. including 94,186 children aged 1, 5 to 5 years up to 60 months in the northern regions of Vietnam found the prevalence of ASD in these regions of $0.415 \%$ (Klin et al., 2015). This is higher than the figures presented in previous surveys in Vietnam (i.e. $0.46 \%$ in $2007,0.416-0.52 \%$ in $2013-2014$ ), which indicates that the prevalence of ASD among children in Vietnam may have increased, which is in line with the current global ASD trend. (Hoang et al., 2019). Increasing degree of urbanization was associated with higher risk of ASD (Park et al., 2016). According to a 2019 study, the frequency of recorded ASDs in Vietnam was significantly higher (almost twice as high) among the urban population in comparison with residents of villages. The likelihood of ASD among boys born to families living in rural areas is more than three times higher than the risk of developing ASD in girls from families living in cities (Lauritsen et al., 2014).

\section{Etiology and Symptoms}

ASD is not an isolated disorder. It is now widely regarded as a multifactorial disease resulting from genetic and non-genetic risk factors and their interactions (Wang et al., 2017). Evidence for genetic variants in the etiology of ASD includes genes implicated in mental retardation and neuropsychiatric disorders, genes for common pathways and genes for ASD risk, the multigenic contribution of rare or common variations, DNA mutations, and environmental influences on gene expression and / or protein function. (Taylor et al., 2016).

Connection between ASD and perinatal period is proved. Risk factors for the development of ASD in the prenatal period are considered the age of the child's parents $\geq 35$ years, the parents' belonging to the Asian race, the presence of arterial hypertension, gestational diabetes, prenatal complications such as the threat of miscarriage and prenatal bleeding. Among the risk factors for the perinatal period, there is a cesarean section, a 
significant number of pregnancies in the mother's history, weakness of labor, breech presentation of the fetus, the development of preeclampsia in a pregnant woman and distress syndrome in the fetus. In the postpartum period, factors contributing to the development of ASD are newborn malnutrition, the development of postpartum hemorrhage, the male sex of the newborn, and congenital brain anomalies. (Devlin and Scherer, 2012).

If biomarkers cannot be obtained, the diagnostic criteria for ASD include the behavioral characteristics of the person. The "gold standard" in the diagnosis of ASD is considered to be a clinical diagnosis formed in accordance with generally accepted systems of diagnostic classification and assessment criteria. Unified cognitive tests and developmental assessment or cognitive testing are the most appropriate and standardized. The final result of the assessment underlies the formation of subsequent diagnostic algorithms in relation to a particular patient. The accuracy of the assessment increases the likelihood of correct diagnosis and is necessary for the development of further tactics in relation to the patient. (American Psychiatric Association, 2013).

Diagnostic criteria (Ha et al., 2014):

A. Symptoms must be present in the early developmental period.

- Violations in verbal behavior

- Anomalies of non-verbal communication

- Delayed development, difficulties in the formation of social relationships.

B. The presence of patterns of behavior and actions that tend to be repetitive and are characterized by the presence of at least two of the following factors from the following list:

- Repetitive and stereotyped physical activity or speech

- Limited scope of interest

- Presence of a tendency to perceive non-perception of certain sensory environmental factors.

C. The presence of those listed in the early period of development is mandatory.

D. Symptoms cause clinically significant impairments in social, occupational, or other important areas of current functioning.

E. These impairments cannot be better explained by mental retardation (impaired intellectual development) or general developmental delay. Mental retardation and autism spectrum disorder are often associated with each other, resulting in a comorbid diagnosis of the autism spectrum.

It is necessary to indicate the presence or absence of the following clinical signs:

- Disorders of intelligence

- Language disorders

- Hereditary diseases and diseases caused by the influence of the environment

- Other pathologies of nervous development, behavioral or mental disorders

- Catatonia

\section{MATERIAL AND METHODS}

A prevalence study was made of children at age from 12-72 months old in some regions representing 20 districts and towns of Nghe An province from August 2011 to August 2013. 
Medical management includes typical antipsychotics, atypical antipsychotics, antidepressants, selective serotonin reuptake inhibitors, $\alpha 2$-adrenergicagonists, $\beta$ adrenergic antagonist, mood stabilizers, and anticonvulsants (McPheeters et al., 2011). Antipsychotics have been effective in treating repetitive behaviors in children with ASD; however, there was insufficient evidence for efficacy and safety in adolescents and adults (Richards et al., 2012)

The procedures followed were in accordance with the ethical standards of the responsible committee on human experimentation (institutional or regional) and with the Helsinki Declaration of 1975, as revised in 2000. All the patients of Nghe An province, Vietnam did agree to participate in the experiment and do not deny the results of the experiment to be provided in the research paper. The minors' parents and guardians do not deny the results of the experiment to be provided in the research paper.

\section{RESULTS}

400 preschool teachers from 187 schools were trained to identify signs of ASD, $49 \%$ of which had good results and skills to work with potentially autistic children (Table $1)$.

Table 1. The results of preschool teacher training for identifying autism spectrum disorder.

\begin{tabular}{lllcll}
\hline No. & City, district, town & $\begin{array}{c}\text { Number of } \\
\text { Classes }\end{array}$ & $\begin{array}{c}\text { Number of } \\
\text { trainees }\end{array}$ & Good & Output \\
\hline 1 & Vinh & 2 & 80 & $55 \%$ & $45 \%$ \\
2 & Dien Chau & 2 & 80 & $57 \%$ & $43 \%$ \\
3 & Quynh Luu & 2 & 80 & $59.5 \%$ & $40.5 \%$ \\
4 & Nghia Dan & 1 & 40 & $45 \%$ & $55 \%$ \\
5 & Thanh Chuong & 1 & 40 & $46 \%$ & $54 \%$ \\
6 & Tan Ky & 1 & 40 & $45 \%$ & $55 \%$ \\
7 & Quy Chau & 1 & 40 & $46 \%$ & $54 \%$ \\
& Total & 10 & 400 & $49 \%$ & $51 \%$ \\
\hline
\end{tabular}

A total of 441 children with autistic signs and symptoms were discovered after teachers learned how to identify and properly behave with such children (Tables 2 and 3).

Table 2. Number of children assigned by trained preschool teachers to the autism spectrum disorder (ASD) department.

\begin{tabular}{lllrl}
\hline No. & District, city & Number of children & \% & P* \\
\hline 1 & Vinh & 251 & 56.9 & \\
2 & Dien Chau & 55 & 12.5 & $<0.01$ \\
3 & Quynh Luu & 51 & 5.0 & \\
4 & Nghia Dan & 22 & 5.2 & \\
5 & Thanh Chuong & 23 & 4.5 & \\
6 & Tan Ky & 20 & 4.3 & \\
7 & Quy Chau & 19 & 100 & \\
& Total & 441 & &
\end{tabular}


Among 441 children with autistic signs being introduced by preschool teachers, 154 children $(34.9 \%)$ were treated.

Table 3. Number of children treated in the autism spectrum disorder department.

\begin{tabular}{lllrl}
\hline No. & District, city & Number of children & \% & P* \\
\hline 1 & Vinh & 91 & 59.1 & \\
2 & Dien Chau & 21 & 13.6 & \\
3 & Quynh Luu & 15 & 9.7 & $<0.01$ \\
4 & Nghia Dan & 9 & 5.8 & \\
5 & Thanh Chuong & 7 & 3.5 & \\
6 & Tan Ky & 6 & 3.9 & \\
7 & Quy Chau & 5 & 100 & \\
& Total & 154 & & \\
\hline
\end{tabular}

\section{Distribution of autistic children by age, gender and geographic region}

As expected, the most common group of children who had ASD symptoms were children 18-24 months (35.4\%) (Table 4 ).

Table 4. Distribution of children with autism treatment by age.

\begin{tabular}{llcc}
\hline Variable & n & \% & P* \\
\hline 2-year-old children (18-24 months) & 81 & 35.4 & \\
3-year-old children (25-36 months) & 66 & 28.8 & $<0.05$ \\
4-year-old children (37-48 months) & 37 & 16.1 & \\
5-year-old children (49-60 months) & 23 & 10.1 & 9.6 \\
6-year-old children (61-72 months) & 22 & 100 & \\
Total & 229 & & \\
\hline
\end{tabular}

The ASD incidence rate for boys and girls was 75.5 and $24.5 \%$ respectively, similar to the worldwide trend (Table 5).

Table 5. Distribution of children with autism treatment by gender.

\begin{tabular}{llcll}
\hline Gender & N & \% & Age average & P* \\
\hline Male & 173 & 75.5 & $3.27 \pm 1.29$ & $<0.05$ \\
Female & 56 & 24.5 & $3.65 \pm 1.56$ & \\
Total & 229 & 100 & $3.46 \pm 1.43$ & \\
P & & $<0.05$ & & \\
\hline
\end{tabular}

Table 6. Children living in cities were the most affected by ASD $41.5 \%$.

\begin{tabular}{lrrr}
\hline Variable & n & \% & P \\
\hline City & 95 & 41.5 & \\
Delta & 72 & 31.4 & $<0.05$ \\
Mountaint region & 21 & 9.2 & \\
Alpine region & 41 & 17.9 & \\
Total & 229 & 100.0 & \\
\hline
\end{tabular}


Following treatment, severe ASD levels decreased from $89.5 \%$ ] to $45 \%$. The fact decrease in severe ASD indicates the correctness and feasibility of diagnosis and therapy (Table 7).

Table 7. The level of psychological improvement after intervention in cases of autism spectrum disorder.

\begin{tabular}{|c|c|c|c|c|c|}
\hline \multirow{2}{*}{ Variable } & \multicolumn{2}{|c|}{ Before intervention } & \multirow{2}{*}{\multicolumn{2}{|c|}{$\begin{array}{c}\text { After intervention } \\
\%\end{array}$}} & \multirow[t]{2}{*}{$\mathbf{p}$} \\
\hline & $\mathbf{N}$ & $\%$ & & & \\
\hline Mild and moderate ASD & 24 & 10.5 & 126 & 55.0 & $<0.01$ \\
\hline Severe ASD & 205 & 89.5 & 103 & 45.0 & $<0.01$ \\
\hline Total & 229 & 100.0 & 229 & 100.0 & \\
\hline CARS scale & $\overline{X 4} 0.82$ & SD 3.55 & 35.93 & 3.81 & $<0.01$ \\
\hline
\end{tabular}

The decrease in severe ASD indicates the correctness and feasibility of diagnosis and therapy.

\section{DISCUSSION}

ASD is traditionally considered by Vietnamese specialists not only as a disease, but also as a problem of a family with a child with ASD. Children with ASD and their families are often discriminated against. Parents of children with ASD use not only medical, but also religious methods in the treatment of children. However, the problem for families with children with ASD is the availability and quality of necessary medical care. The development of diagnostic protocols adapted to social requirements and economically affordable treatment methods is especially urgent. (Tran and Weiss, 2018). At present, in Vietnam, is no oversight of ASD services. Literally any individual or agency can have whatever services they want, without any government oversight. Even though the majority of treatment interventions included EBP techniques, $17.6 \%$ of non-EBP techniques were reported. These results are likely due to their ineffectiveness, but also to significant costs, as well as potential side effects and health risks. In addition, the low overall effectiveness of these approaches in treatment is a possible reason for the low trust of families with children with ASD in medicine and educational systems. Concerning the intervention approach, EBP is considered "appropriate"; however, only $27.9 \%$ of agencies met these criteria (Samms-Vaughan et al., 2017).

\section{Diagnostic and Treatment of ASD}

Two versions of the Childhood Autism Scales (CARS) have been developed: for patients with an IQ of 79 or less and for patients with an IQ of 80 and above. (Schopler et al., 2010; Chlebowski et al., 2010). Traditionally, the following domains are distinguished among CARS: social relationships; the ability to reproduce and imitate; level of emotional response; physical activity; ability to adapt to change; visualization reaction; reaction of the hearing organs; taste, smell and sensory response; fear or nervousness; activity of verbal communication; ability in non-verbal communication; the severity of the intellectual reaction. (Perera et al., 2017). Another modern sensitive methods for ASD diagnostic: Pictorial Autism Assessment Schedule (PAAS) (Choueiri and Wagner, 2015), 
Rapid Interactive Test for Autism in Toddlers (RITA-T) (Zwaigenbaum et al., 2015), Screening Test for Autism in Two-Years-Old (STAT) (Richards et al., 2012), Modified Checklist for Autism in Toddlers (M-CHAT) (Richards et al., 2012).

Screening for ASD is important between the ages of 18 and 24 months, as supported by a considerable evidence. Early screening (before 24 months) can produce a significant number of false positives, but still has some benefit. (Stenberg et al., 2014). It is generally accepted among specialists and experts in the field of ASD that the individual approach to the treatment of patients is considered. The treatment of individual symptoms, including aggression, agitation, inattention, irritability, tendency to self-harm, hyperactivity, makes the treatment of both the health care system and the education more effective. (Adler et al., 2015).

ASD is a pathology predisposing to self-harm, which is mainly associated with impulsivity, hyperresponsiveness and speech impairments inherent in ASD (Volkmar et al., 2014).

Drug correction of ASD involves the use of antipsychotics, antidepressants, selective serotonin reuptake inhibitors, $\alpha 2$-adrenergic agonists, $\beta$-adrenergic antagonists, anticonvulsants, and mood stabilizers (McPheeters et al., 2011). With regard to antipsychotic drugs, there is evidence of their effectiveness in treating recurrent ASD in children, and there is no evidence base regarding their effectiveness and safety in adolescents and adults with ASD (Richards et al., 2012). Due to the fact that RAS symptoms remain refractory to any type of treatment, such patients need Deep Brain Stimulation as alternative method of treatment (McPheeters et al., 2011).

\section{Recommendations and Tactics}

- When assessing the development of all children with identified psychiatric pathology, questions related to ASD should be applied.

- If, during screening, the identified symptoms of ASD have a high grade, it is necessary to consider the possibility of a more thorough diagnosis.

- Clinical professionals should consider the use of interdisciplinary approaches for patients with ASD. essential.

- Help and advice from a clinician to family members with a child with ASD is

- Consideration should be given to the use of pharmacotherapy if symptoms are detected in a child with ASD or if there is concomitant pathology.

- An active role of the doctor is required in the long-term planning of treatment and psychological assistance for families and children with ASD.

- It is necessary for doctors to use additional and consider alternative methods in relation to patients with ASD.

\section{CONCLUSION}

ASD is a complex and systemic pathology. In Nghe An, there has been no research on the epidemiology of ASD in children. Therefore, the detection and organization of treatment and teaching of children are very necessary in order to create conditions for 
children to develop a fuller personality, integrate into the community, and reduce the burden for themselves, their family, and society.

\section{ACKNOWLEDGMENTS}

The authors would like to express their special thanks to Nghe An Pediatric Hospital for the financial support.

\section{CONFLICTS OF INTEREST}

The authors declare no conflict of interest.

\section{REFERENCES}

Adler BA, Wink LK, Early M, Shaffer R, et al. (2015). Drug-refractory aggression, self-injurious behavior, and severe tantrums in autism spectrum disorders: A chart review study. Autism. 19(1): 102-106. DOI: $10.1177 / 1362361314524641$.

American Psychiatric Association (2013). Diagnostic and statistical manual ofmental disorders. 5th ed. Arlington, VA.

Baio J, Wiggins L, Christensen DL, Maenner MJ, et al. (2018). Prevalence of Autism Spectrum Disorder Among Children Aged 8 Years - Autism and Developmental Disabilities Monitoring Network, 11 Sites, United States, 2014. Morb. Mort. Week. Rep. Surv. Summ. (Washington D.C.: 2002). 67(6): 1-23. DOI:10.15585/mmwr.ss6706a1.

Baxter AJ, Brugha TS, Erskine HE, Scheurer RW, et al. (2015). The epidemiology and global burden of autism spectrum disorders. Psychol. Med. 45(3): 601-613.

Chlebowski C, Green JA, Barton ML and Fein D (2010). Using the childhood autism rating scale to diagnose autism spectrum disorders. J. Autism Dev. Disord. 40(7): 787-799.

Choueiri R and Wagner S (2015). A New Interactive Screening Test for Autism Spectrum Disorders in Toddlers. $J$. Pediatr. 167(2): 460-466. DOI/10.1016/j.jpeds.2015.05.029.

Devlin B and Scherer SW (2012). Genetic architecture in autism spectrum disorder. Curr. Op. Gen. Dev. 22(3): 229-237. DOI:10.1016/j.gde.2012.03.002.

Ha VS, Whittaker A, Whittaker M and Rodger S (2014). Living with autism spectrum disorder in Hanoi, Vietnam. Soc. Sci. Med. 120: 278-285. DOI:10.1016/j.socscimed.2014.09.038.

Hoang VM, Le TV, Chu TTQ, Le BN, et al. (2019). Prevalence of autism spectrum disorders and their relation to selected socio-demographic factors among children aged 18-30 months in Northern Vietnam, 2017. Int. J. Ment. Health Syst. 13: 29. DOI: 10.1186/s13033-019-0285-8.

Hossain MD, Ahmed HU, Jalal Uddin MM, Chowdhury WA, et al. (2017). Autism Spectrum disorders (ASD) in South Asia: a systematic review. BMC Psychiatry. 17(1): 281.

Klin A, Klaiman C and Jones W (2015). Reducing age of autism diagnosis: developmental social neuroscience meets public health challenge. Revista de Neurol. 60 (Suppl. 1): 3-11.

Lauritsen MB, Astrup A, Pedersen CB, Obel C, et al. (2014). Urbanicity and autism spectrum disorders. J. Autism Dev. Disord. 44(2): 394- 404.

McPheeters ML, Warren Z, Sathe N, Bruzek JL, et al. (2011). A Systematic Review of Medical Treatments for Children with Autism Spectrum Disorders. Pediatrics. 127(5): 1312-1321. DOI: 10.1542 / peds.2011-0427.

Park HR, Lee JM, Moon HE, Lee DS, et al. (2016). A Short Review on the Current Understanding of Autism Spectrum Disorders. Exp. Neurobiol. 25(1): 1-13. DOI:10.5607/en.2016.25.1.1.

Perera H, Jeewandara KC, Seneviratne S and Guruge C (2017). Culturally adapted pictorial screening tool for autism spectrum disorder: A new approach. World J. Clin. Pediatr. 6(1): 45-51. doi:10.5409/wjcp.v6.i1.45.

Richards C, Oliver C, Nelson L and Moss J (2012). Self-injurious behaviour in individuals with autism spectrum disorder and intellectual disability. J. Intellect. Disabil. Res. 56: 476-489. DOI:10.1111/j.1365- 2788.2012.01537.x.

Samms-Vaughan M, Rahbar MH, Dickerson AS, Loveland KA, et al. (2017). The diagnosis of autism and autism spectrum disorder in low- and middle-income countries: Experience from Jamaica. Autism Int. J. Res. Pract. 21(5): 564-572. DOI:10.1177/1362361317698938.

Schopler E, Van Bourgondien M, Wellman J and Love S (2010). Childhood Autism Rating Scale, Second edition (CARS2): Manual. Los Angeles: Western Psychological Services.

Stenberg N, Bresnahan M, Gunnes N, Hirtz D, et al. (2014). Identifying children with ASD at 18 months. Pediatr. Perinat. Epidemiol. 28: 255-262. DOI:10.1111/ppe.12114. 
Taylor L, Brown P, Eapen V, Midford S, et al. (2016). Autism Spectrum Disorder Diagnosis in Australia: Are we meeting Best Practice Standards? Autism Co-operative Research Centre, Brisbane.

Tran CV and Weiss B (2018). Characteristics of Agencies Providing Support Services for Children with Autism Spectrum Disorders in Vietnam. IJSSH. 8(4): 116-121. DOI:10.18178/ijssh.2018.V8.946.

Volkmar F, Siegel M, Woodbury-Smith M, King B, et al. (2014). Practice Parameter for the Assessment and Treatment of Children and Adolescents with Autism Spectrum Disorder. J. Am. Acad. Child Adolesc. Psychiatry. 53(2):237257. DOI:10.1016/j.jaac.2013.10.013.

Wang C, Geng H, Liu W and Zhang G (2017). Prenatal, perinatal, and postnatal factors associated with autism: A metaanalysis. Medicine. 96(18): e6696. DOI:10.1097/MD.0000000000006696.

World Health Organization. Autism spectrum disorders. (2019). Retrieved from http://www.who.int/mediacentre/factsheets/autism-spectrum-disorders/en/.

Yen NTH (2014). Study on Early Intervention and Inclusive Education for Autistic Children in Vietnam at Present and in the 2011-2020 Period. Hanoi: Hanoi National University of Education; p. 373.

Zwaigenbaum L, Bauman ML, Fein D, Pierce K, et al. (2015). Early screening of autism spectrum disorder: Recommendations for practice and research. Pediatrics. 136: 41-59. DOI:10.1542/peds.2014-3667D. 